\title{
Study of Integrated Social Vulnerability Index SoVI int of Hilly Region of Uttarakhand, India
}

\author{
Dilip KUMAR $^{1 *}$, Rajib KUMAR BHATTACHARJYA ${ }^{2}$ \\ ${ }^{1}$ Department of Civil Engineering B Pant Engineering College, Pauri, Uttarakhand, 781039, India \\ ${ }^{2}$ Department of Civil Engineering, IIT Guwahati, Assam, 781039, India
}

\begin{abstract}
The hilly regions of India have suffered many disasters, both natural and anthropogenic. In the hilly state like Uttarakhand, the hazards like flash flood, forest fires, and landslide affect the community at the large scale. These hazards cause severe physical injuries, loss of life, and at large scale property damage. To understand the impact of such natural hazards, we need to examine vulnerability of the society, so that we can define vulnerability as the status of a community to prevent, mitigate, prepare for or respond to a natural and a man-made hazard. The absence of coping strategies, which is also known as resilience, has altered the vulnerability of a community. Thus, vulnerability index of a community has to be calculated considering physical, social, economic and environmental factors associated with the community. This research paper tries to find out an integrated social vulnerability factor. The proposed integrated social vulnerability factor is determined by considering various factors, such as physical, social, economic, and environmental. All these factors increase the susceptibility of a community to the impact of hazards. Poverty, occupation, child population, literacy rate, disability, marginalization, and inequities in wealth distribution of a society or community will also change the social vulnerability. Proposed Integrated social vulnerability index for the hilly terrain of Uttarakhand incorporated local technical knowledge insight and skills, so that local people and local administration are able to identify problems and can offer a solution to resist future emergencies i.e. the proposed social vulnerability indicator will support state, local, and traditional disaster management officials to determine areas of the most sensitive populations and better mitigation operation can be performed in case of disaster.
\end{abstract}

Keywords - Integrated vulnerability; social; vulnerability index.

\begin{tabular}{ll}
\hline Nomenclature & \\
$D D S$ & District Development Score \\
$S o V I_{\text {int }}$ & Integrated social vulnerability index \\
$P_{v}$ & Physical vulnerability \\
$S_{v}$ & Social vulnerability \\
$E n_{v}$ & Environmental vulnerability \\
$E c_{v}$ & Economic vulnerability \\
$A R$ & Approaching roar \\
$T V$ & Total number of vehicles \\
\hline
\end{tabular}

* Corresponding author.

E-mail address: Jhadilip27@gmail.com

C2020 Dilip Kumar, Rajib Kumar Bhattacharjya.

This is an open access article licensed under the Creative Commons Attribution License (http://creativecommons.org/

licenses/by/4.0), in the manner agreed with Sciendo. 


\begin{tabular}{|ll|}
\hline$C I$ & Composite index \\
ha & Hectare \\
JJA & June, July, August \\
IPCC & Intergovernmental Panel on Climate Change \\
\hline
\end{tabular}

\section{INTRODUCTION}

The Uttarakhand is a hilly state of India [1]. It has a rich culture state backed by a rich floral variety, plants, wood cover as well as the strong and stable ecology [2]. Recognizing such potential of resource in the state, the central government of India has stated Uttarakhand as a green state of the country [2]. Recently, the increased recurrence and extent of flash floods and landslides events in different districts of the Uttarakhand are disturbing the local community [1], [3]. These have caused a lot of damage to the people and the infrastructure of the Uttarakhand. The destructive flash flood occurred in Kedarnath, cloudburst event in Bhagirathi are notable disasters of the state. Along with these natural calamities, Uttarakhand has also become famous for "ghost village" i.e. the people from several villages are migrating to some other places. A report appeared in the national daily, 'The Hindu', last year a total of 500 villages of the state become ghost village. As such, it is necessary to find out the root cause of these problems faced by the state. This study focuses on the deriving a map for the hilly districts of Uttarakhand showing the vulnerability incorporating natural, social and economic indicators. In general terms, the vulnerability is described as a chance of being damaged of a person, a system or any environmental related projects which is disclosed to a risk and sensitive to lose [4], [5].

Persson et al. defined vulnerability in a combined result of different factors like physical factors, economic factors, the political or social factors to the community due to any kind of disaster [6]. Some researcher also defined vulnerability on the basis of the political ecological concept as it is the relationship that people have with their environment [7]. Ballica et al. stated that the vulnerability is not only important for the survival of the societies to severe floods, but also for their adjustment to climate change[4], [8], [9]. Before starting the discussion on social vulnerability, we should know the basic definition and meaning of words which are similar in nature, but have different meaning in terms of hazard. Risk is the probability or chance of destruction; Hazard is a condition affecting the risk of loss; Vulnerability is the degree to which individuals or objects are expected to be affected; and Resilience are those resources in place that will reduce the implements of hazards [10]-[12]. Table 1 is showing these words with their definitions.

TABLE 1. DifFERENT TERMS RELATED TO HAZARD AND VULNERABILITY

\begin{tabular}{lll}
\hline Hazard & $\begin{array}{l}\text { the possible warning to humans and } \\
\text { their welfare associated with them. }\end{array}$ \\
\hline+ & $\begin{array}{l}\text { respond to a natural and a man-made } \\
\text { hazard. }\end{array}$ \\
\hline Vulnerability & probability of occurrence of hazard. \\
\hline Risk & & \\
\hline Disaster & $:$ & the consciousness of a risk. \\
\hline
\end{tabular}


The present study is trying to prepare a map for the state of Uttarakhand considering social vulnerability, based on different factors as discussed later. The people may be vulnerable due to lack of access to knowledge, education, and technology. For better visualization of the social vulnerability, we should carry out the importance and relevance of different factors under social and physical heads and their interconnections. The correlation between different factors should explain the impact of the natural hazard. Integrated social vulnerability index ( $\left.S o V I_{\text {int }}\right)$ consists of various social, economic and physical indicators, such as age (children or elderly), gender, disability, employment, housing characteristics, participation in governmental activities, participation in decision making, etc.

The present study focused only on the hilly part of the state since, the hilly terrain has different hydrographical-geographical challenges with comparisons with the plain area. As, for example, a flash flood event, cloudburst and outmigration's are the unique phenomena occurring amongst the different parts of the world in hilly terrain [13]-[16]. Thus, in the present study, an effort has been made to utilize the potential of remote sensing, GIS techniques, and put them together with the value of the indicator to find out the solution for disaster management in the hilly terrain of Uttarakhand. The proposed integrated social vulnerability index is able to provide guidelines to policymakers at the districts level regarding vulnerability assessment of the region in view of social aspects and also provide a link of the sustainable development of hilly terrain of the Uttarakhand.

\section{Methodology}

\subsection{Study Area}

Uttarakhand, the 27 th state of India, located in the mighty Himalayas. It lies between $28^{\circ} 43^{\prime} \mathrm{N}$ and $31^{\circ} 27^{\prime} \mathrm{N}$ latitude and $77^{\circ} 34^{\prime} \mathrm{E}$ and $81^{\circ} 02^{\prime}$ E longitude (Fig. 1).

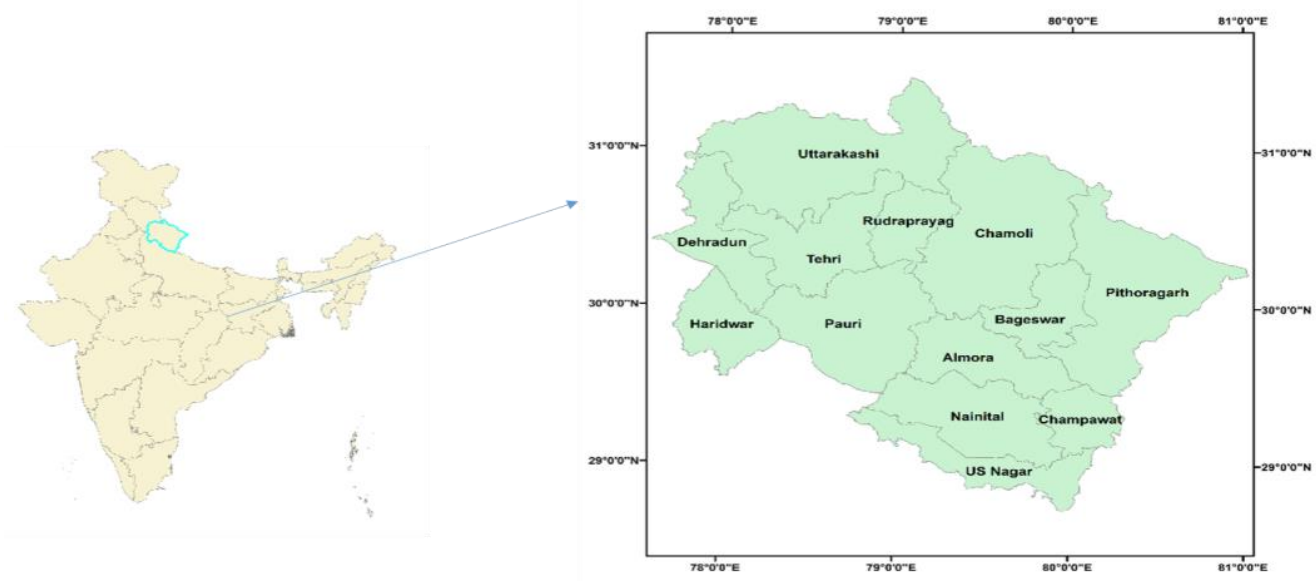

Fig. 1. Map showing area of interest.

The state spread over an about 53483 sq.km of geographical area. Out of the total geographical area, the mountains and hills cover about 46035 sq.km of area. In the present analysis only hilly part of the state is taken into consideration, since the hilly part accounts approximate $90 \%$ of the 
total area of the state. The people living there are facing adverse situation as compared to other parts of the state.

\subsection{Choice of Indicators for Integrated Social Vulnerability Index}

In the present study, the vulnerability factors are classified through the application of an indicator-based system that considers the social, physical, economic and environmental aspects, as shown in Fig. 3. A variable or indicator is defined as a unit which is a part of a specific system and which is able to provide information regarding the susceptibility, exposure, and resilience. Indicators have been widely known as analysis engines which transform unprocessed data into information. Their application shows how well they describe the information related with socioeconomic, physical, and environmental factors, including the administration policies. In terms of vulnerability evaluation, the principal objective of the vulnerability analysis is the description and recognition of vulnerability and its different composite factors. In such type of analysis, the most challenging task is the selection of indicators. The selection of indicators in the present study is based on the availability of data, previous research work, survey and expert judgments where applicable [17]. The survey was performed amongst the engineering colleges of Uttarakhand, which is based on their knowledge about different factors of Vulnerability. The detail approaching procedure was shown in Fig. 2.

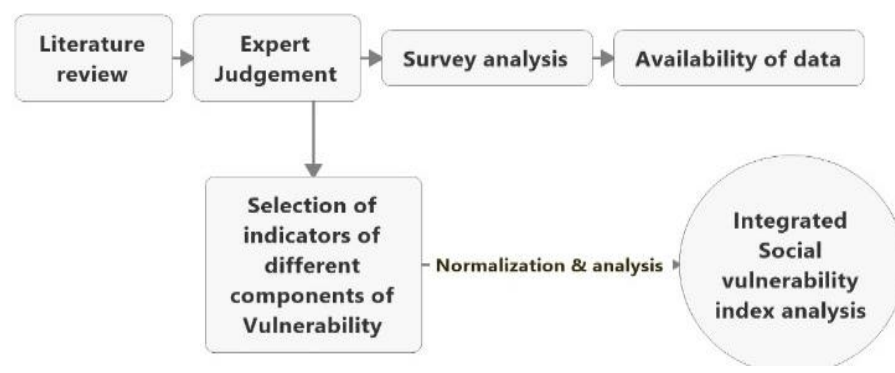

Fig. 2. Social vulnerability index analysis approach.

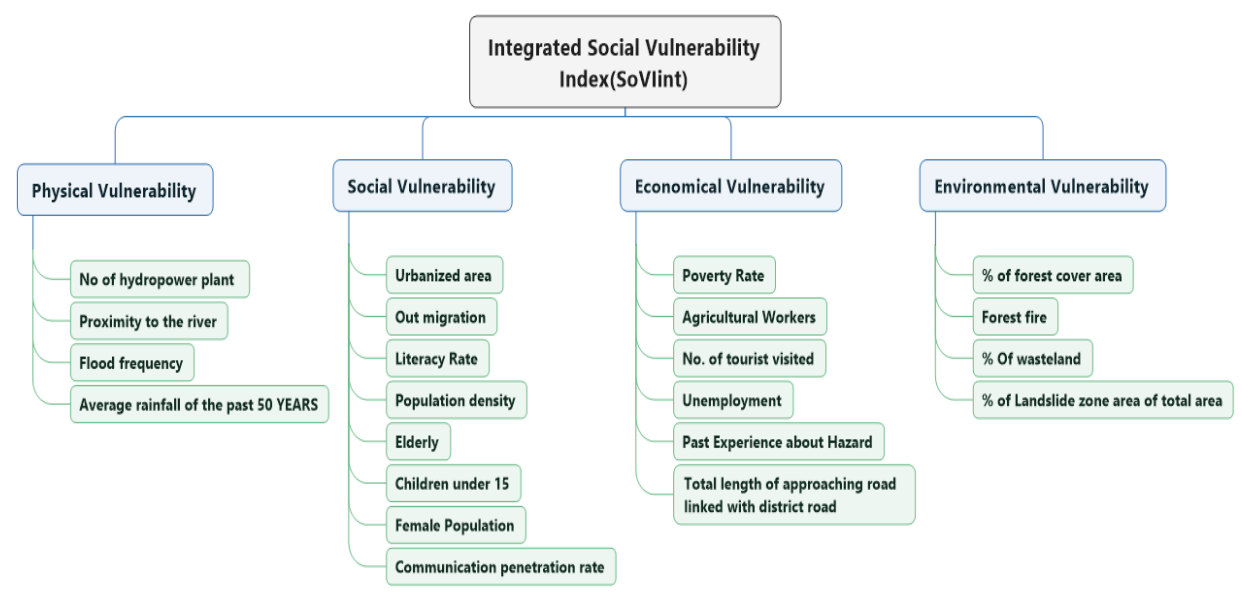

Fig. 3. Different components and sub components of Social vulnerability index. 


\subsubsection{Physical Vulnerability}

The term physical vulnerability defines the possibility or the potential of a given segment or element to be altered or damaged under a natural hazard such as a flood, landslide or earthquake[18]. The physical vulnerability of any region depends on its closeness to the root and origin of the hazards [19]. For an example, if a region extends near the river edge or lies at the steep hill slope, it makes the area of interest more exposed to disasters as corresponded to the areas that are far away from the beginning of the disaster. This component of vulnerability also involves the problem in utilization to water resources for local people, communications hurdles, hospitals access, roads and bridges as used for transportation. Furthermore, the lack of proper outlining, use of poor-quality building construction materials, use of unskilled labour and the non-engineered building construction process resulted in the newly constructed building become insecure and as a result, it is easily exposed to earthquakes, floods, landslides and other natural calamities. In the present study, total five indicators are selected under subhead of physical vulnerability, which is most suitable for the study area and data availability. The factors like proximity to river (m), average rainfall (mm) in monsoon season (June-July-August) in last 50 years, flood frequency in cloud bursting/flash flood ( $\geq 270$ cumec), no. of hydropower plants and area with altitude more than $3000 \mathrm{~m} \mathrm{( \% )}$ are considered as indicators under physical vulnerability. Some indicators have a positive relationship with vulnerability and some have a negative relationship.

\subsubsection{Economic Vulnerability}

The economic vulnerability is defined as the exposure of an area to exogenous shocks like flood, earthquake or any hazard [20], [21]. The economic viability of a society or region can be judged based on the sources of income of the people [22]. It can also be visualized with the ease of way and command over the means of creation (e.g. agricultural land, cattle, watering, resources etc.), and the availability of native sources in that area. In the present study, the factors like poverty rate, unemployment, the population of the agricultural worker, past occurrences of the hazard, the total length of approach road linked with major district road $(\mathrm{km})$ are selected to represents the economic vulnerability of the study area.

\subsubsection{Environmental Vulnerability}

The faster growth rate of Human population has stimulated the global warming and thereby increased the number and intensity of severe climatic issues like flash flood and drought [11], [23]. On a regional scale, deforestation and urbanization have recognizable impacts on regional rainfall patterns and are also associated with the appearance of aridity [24]. Any factor vulnerable to environment adversely affects climate, especially the faster growth of urban areas and construction of high floor buildings[25], [26]. A thorough study associated with environmental vulnerability is needed for the better future climatic condition. The percentage of forest cover, no. of the agricultural and soil service center, percentage of wasteland, forest fire (total affected area, ha), the percentage of the landslide zone area are chosen as the indicators for assessing environmental vulnerability.

\subsubsection{Social Vulnerability}

The social viability to physical events is highest among the poverty-stricken population in developing countries. This is mainly due to a shortage of knowledge and sources with which one can take suitable steps [21], [27], [28]. Within this group, the children, female population, elderly people and the disabled persons are supposed to be the most exposed. To have a proper picture of 
social vulnerability, all these factors must be considered. Furthermore, the social vulnerability not only concentrates on the features of individuals but also their connection with the society, explaining the nature of their relationships. In this study, nineteen indicators are selected to study the social vulnerability. Few of them are presented in Fig. 4 and Fig. 5.

\subsubsection{The Interdependency of These Factors on Social Vulnerability}

As discussed earlier, the vulnerability to hazards is influenced by many elements, including age and social status, the stability of communal systems, and area characteristics. The group of people living in flood-prone areas are more vulnerable than those not living there. The women, children and disabled persons are most vulnerable, since at the time of hazard it is very difficult to rescue them [29]-[31]. An area with higher population density is more vulnerable to disaster as casualties are more possible in case of disaster. Places with transportation facilities, health facilities and communication services are good, are less vulnerable as they can manage to mitigate the disaster in case of emergency. The multi-storey buildings and poor houses are also most vulnerable in case of disaster [32]-[34]. In hilly areas of Uttarakhand, many poor-income people were strung in the case of flash flood because they had no personal transportation and public authorities did not provide emergency transport.

\subsection{Computation of Integrated Social Vulnerability Index (SoVI $\left.I_{\mathrm{int}}\right)$}

In general, we can analyse different indicators in two ways:

- Give the same importance to each factor;

- Give an importance to each factor with the help of expert judgments and previous research works and then using analytical hierarchy process and correlation [35].

\subsubsection{Arrangement of Data}

The collected data were arranged in the matrix form with rows representing different districts and columns of the matrix represents different vulnerability factors. In simple terms, we can explain that for P regions/ districts, we have gathered Q numbers of indicators. Again, $X_{i j}$ is the value of the indicator, where $j$ corresponding to region $i$. Since each vulnerability factors have different units, so we make them unit free and for further calculation, the vulnerability indicators were normalized and finally, we get their value between 0 and 1 . After getting the normalized numbers, the corresponding index is created by providing different weights to all factors.

\subsubsection{Normalisation of Indicators Using Operative Association}

Two types of Operative Association are possible between vulnerability and their indicators: firstly, vulnerability increases with the increase (or decrease) in the value of the indicator or vice versa. In the study, two formulas are used to normalize indicator, depending on their operative association with vulnerability. If the vulnerability increases with the factors, the normalization is done using the following formula

$$
Y_{i j}=\frac{\left\{X_{i j}-\operatorname{Min}\left(X_{i j}\right)\right\}}{\left\{\operatorname{Max}\left(X_{i j}\right)-\operatorname{Min}\left(X_{i j}\right)\right\}} .
$$


On the other hand, in case the factors have a decrease mathematical relationship with vulnerability, the normalized score is calculated as:

$$
Y_{i j}=\frac{\left\{\operatorname{Max}\left(X_{i j}\right)-X_{i j}\right\}}{\left\{\operatorname{Max}\left(X_{i j}\right)-\operatorname{Min}\left(X_{i j}\right)\right\}},
$$

where, $X_{i j}$ is the value of $j^{\text {th }}$ indicator $(j=1,2, \ldots, n)$ in the $i^{\text {th }}$ village/district $(i=1,2,3,4)$ and $Y_{i j}$ is the matrix corresponding to the normalized score. It is already mentioned that the estimated value of $Y_{i j}$ lies between 0 and 1 . The value 1 corresponds to that village/ district with maximum value and 0 the village/ district with the minimum value.

\subsubsection{Formulation of Weight Matrix and Collection and Conversion of Indicators into Vulnerability index}

After calculating the generalized scores of different indicators of vulnerability, the vulnerability table is created by providing a different weighting to all indicators. In the literature, we found that different methods were used to give weight to indicators either equal weights (Patnaik and Narain Method) or unequal weights (Iyengar and Sudarshan method). The unequal weights can be calculated by using expert judgment by multivariate statistical techniques. The unequal weights can be calculated by using expert judgment or by multivariate statistical techniques [8], [35]-[38].

In this study, we used the odd method of Iyengar and Sudarshan to give weight to all indicators contributing towards vulnerability. Iyengar and Sudarshan explained the method to find out an equal index from multidimensional data and it was used to rank the districts in terms of their financial enforcement. The proposed method is statistically reliable and equally satisfactory for the development of the proposed index, which is used to study the social vulnerability of Uttarakhand. In Iyengar and Sudarshan method, the value of indicators is hypothesized to change inversely with the variance. The weight of each factor $W_{j}$ is determined by:

$$
W_{j}=\frac{c}{\left[\operatorname{Var}\left(X_{i j}\right)\right]^{0.5}}
$$

where $c$ is a constant i.e.

$$
c=\left(\sum \frac{1}{\left[\operatorname{Var}\left(X_{i j}\right)\right]^{0.5}}\right)^{-1}
$$

The composite vulnerability indicator for social vulnerability factors (physical, economic, environmental, and social) for the $i^{\text {th }}$ district has been obtained as:

$$
V_{i}=\sum W_{j} Y_{i j}
$$


where

$V_{i} \quad$ Composite indicator of $i^{\text {th }}$ district;

$W_{j} \quad$ Weight for each indicator lies between 0 and $1, \sum W_{j}=1$;

$Y_{i j} \quad$ Simplified scores of each factor.

To compare the indices calculated for each vulnerability factor, the sum for each of the factor of physical, economic, environmental and social vulnerability are divided by their corresponding total number of indicators. The composite vulnerability index for each physical factor can be given as:

$$
P h=\frac{\left[\sum W_{j i j} Y_{i j}\right.}{n},
$$

where

$P h \quad$ Integrated vulnerability index of different physical factor;

$W_{j} \quad$ Weight of a single indicator;

$Y_{i j} \quad$ Normalized value of indicator;

$n \quad$ Number of indicators.

Similarly, the composite factors for social, environmental and economic vulnerability are calculated as

$$
\text { Integrated } S o V I=P v+S v+E c v+E n v .
$$

\subsection{Integrated Social Vulnerability Maps}

After getting the indexed value of all the four factors of social vulnerability, like physical, economic, social and environmental, they are fit into ArcGIS 10.4 for preparation of final vulnerability map. The maps are coded with different colour to visualize the vulnerability extent of different hilly districts of Uttarakhand. Fig. 4 and 5 show a part of different social factors selected for the present study.

\subsection{Correlation Analysis Between Different Components of Social Vulnerability Index and Their Factors}

Correlation analysis is a technique of analytical assessment applied to study the effectiveness of a relationship between two, numerically calculated, continuous variables (e.g. distance and displacement) [13], [39]. This correlation analysis useful when we need to determine if there are conceivable links between variables. So, the correlation analysis was performed between the different factors and the corresponding index. The purpose behind this analysis to visualize the significance of each factor in different vulnerability components i.e. social vulnerability, economic vulnerability, environmental and physical vulnerability. 


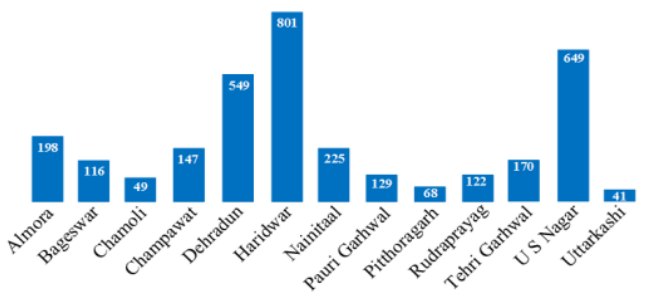

Children under 15 years of age, $\%$

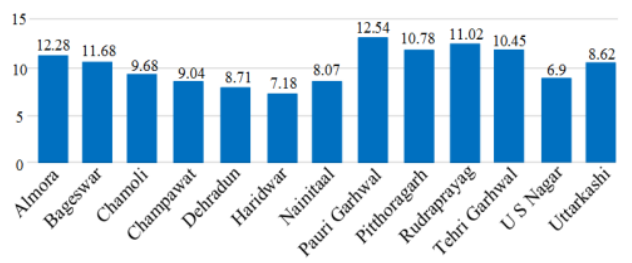

Literate persons, \%

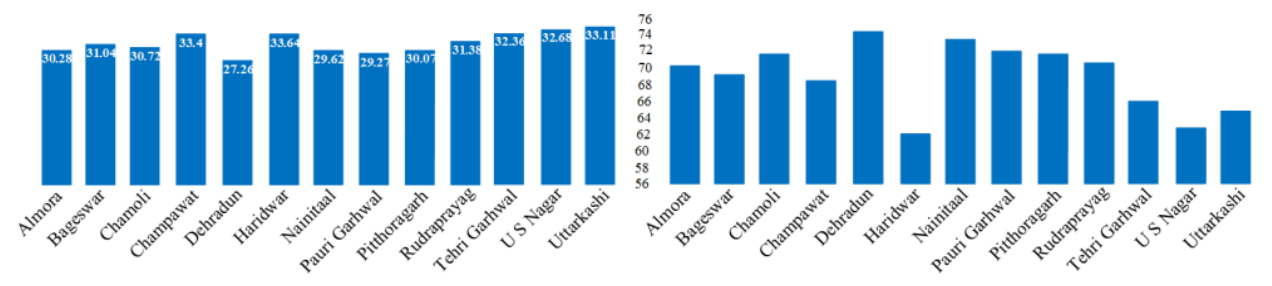

Decadal growth rate, $\%$
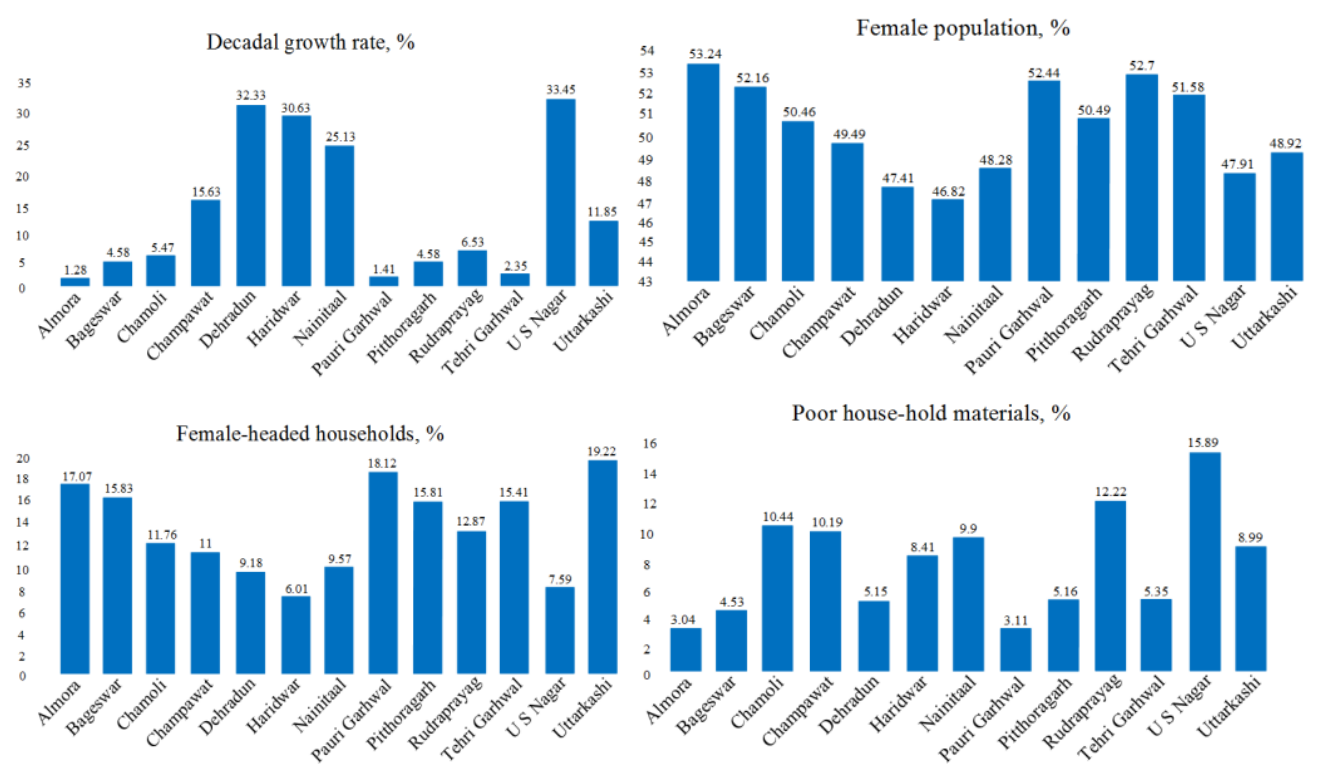

Fig. 4. Different factors selected for Social vulnerability analysis. 
Female-headed houses, \% Poverty rate, \%

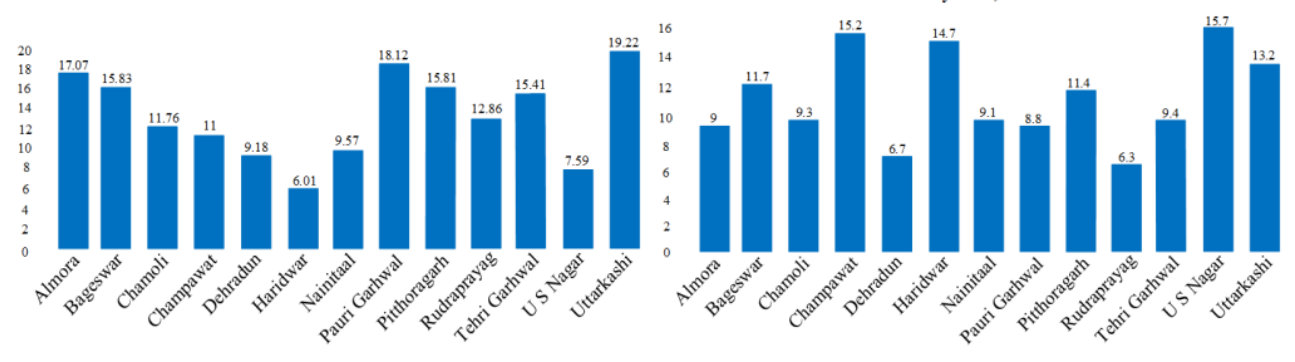

Household sizes $\geq 5$, \%

Disabled persons, \%

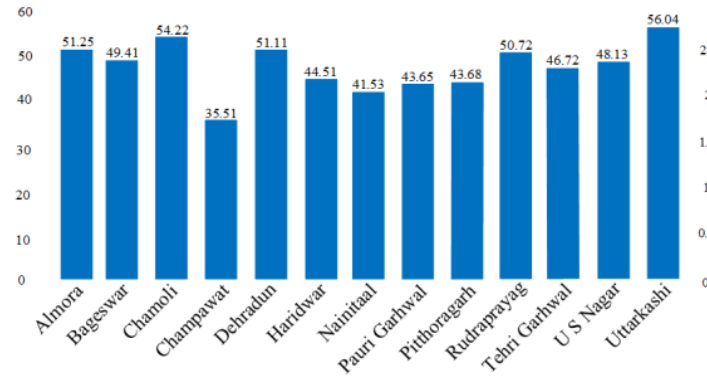

Agricultural workers of total workers, $\%$

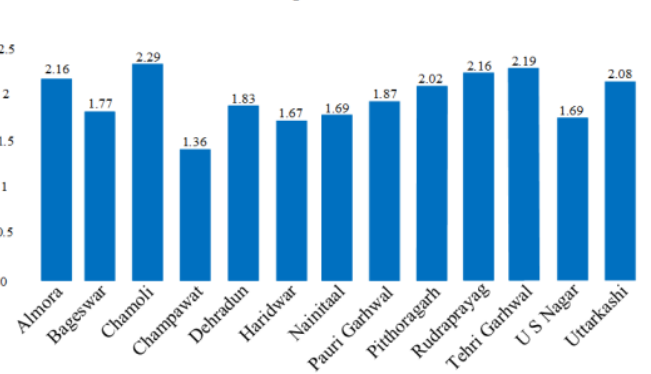

Awareness of hazard, \%

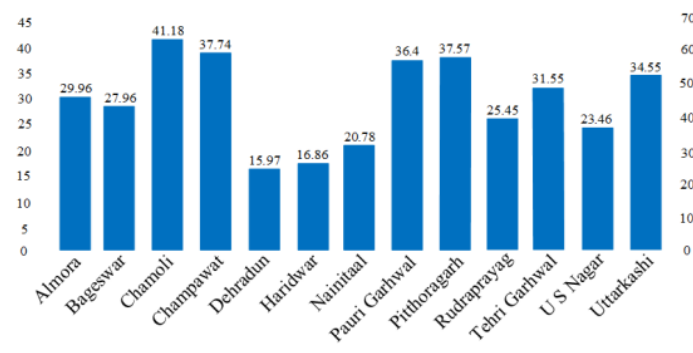

Past occurrences of hazards, \%

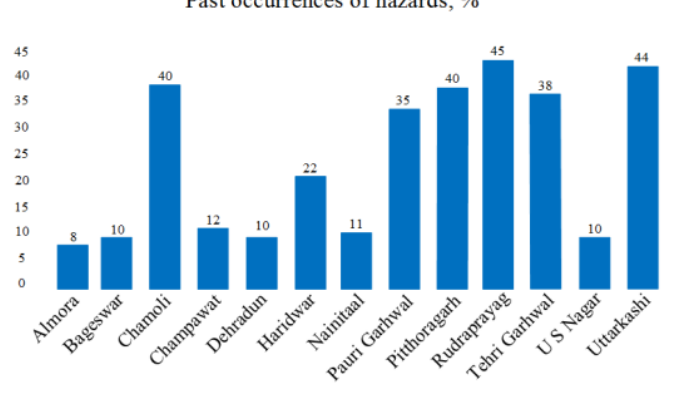

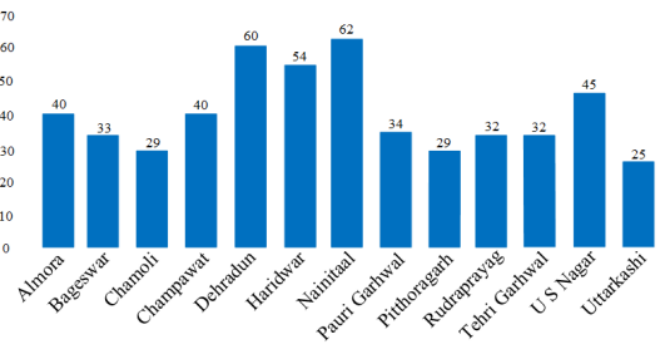

Hydrological factors

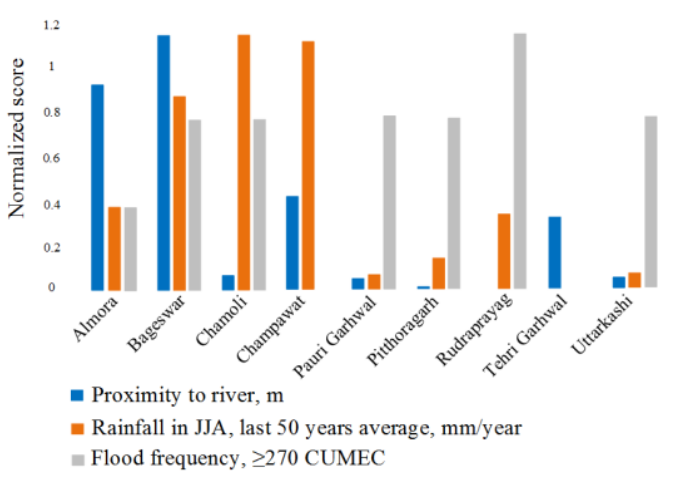

Fig. 5. Different factors selected for Social vulnerability analysis. 
TABLE 2. CORRELATION BETWEEN ECONOMIC VULNERABILITY AND THEIR COMPONENTS

\begin{tabular}{ll}
\hline Poverty Rate & 0.560 \\
\hline Agricultural Workers & 0.797 \\
\hline No. of tourist visited & 0.523 \\
\hline Unemployment, \% & 0.341 \\
\hline Past occurrences of Hazard & 0.274 \\
\hline $\begin{array}{l}\text { Total length of approaching road, connected with districts } \\
\text { road, km }\end{array}$ & 0.533 \\
\hline$E c_{v}$ & 1 \\
\hline
\end{tabular}

If we analyse this correlation, we can find that agricultural workers and poverty rate have greatly influenced each other over economic vulnerability, whereas the past experience of flood and length of approaching roads have reduced the economic vulnerability of the hilly terrain region as shown in Table 3.

TABLE 3. Correlation BETWEEn ENVIRONMENTAL VulNERABILITY AND THEIR COMPONENTS

\begin{tabular}{ll}
\hline$\%$ of forest cover (with Ga) & 0.641 \\
\hline No. of agri. \& soil service centre & 0.184 \\
\hline Forest fire (total affected area, ha) & 0.279 \\
\hline$\%$ Of waste land of total Ga & 0.733 \\
\hline$\%$ of landslide zone area of total area & 0.649 \\
\hline$E n_{v}$ & 1 \\
\hline
\end{tabular}

In case of environmental vulnerability, the soil testing centers and forest cover decreases the vulnerability, whereas the landslide area and wasteland contribute maximum towards the vulnerability. Generally, the forest cover also reduces the erosion capacity and also responsible to reduce the effect of climate change [40]-[42]. The hydrological factors like number of hydropower plants, altitude range and especially flood frequency also play to enhance the social vulnerability in terms of physical vulnerability as mentioned in Table 4.

TABle 4. CoRrelation BETWEen PHYSiCAl VulNERABILITY AND THEIR COMPONENTS

\begin{tabular}{ll}
\hline Proximity to the river, $\mathrm{m}$ & 0.346 \\
\hline Flood frequency ( $\geq 270$ CUMEC) & 0.945 \\
\hline No. of hydropower plants & 0.614 \\
\hline Area with altitude more than $3000 \mathrm{~m}, \%$ & 0.749 \\
\hline Avg. rainfall in the last 50 years in JJA, mm/year & 0.743 \\
\hline$P_{v}$ & 1 \\
\hline
\end{tabular}




\section{RESUlts}

The factors like poverty rate, length of approaching road and education system are better in the plain area in comparison to the fully hilly areas of the state. As a result, Almora district which is located in partial plain area of the state comes with least economic vulnerability. The upper Himalayan district Chamoli has the highest economic vulnerability. The migration rate, unemployment, health services are relatively poor in hilly districts of Uttarakhand. As a result, all the hilly districts are almost in same range of social vulnerability index. The index is varying from 0.021 to 0.024 . It confirms that the all the districts are facing the same social problem. Forest fire and landslide are most common incidents occurring in the upper Himalaya region. These are the major factors for environmental vulnerability. In comparison to the other districts of the state, Chamoli district is most environmentally vulnerable with an index value of 0.14 . Fig. 6 , shown the numerical value of the different components of integrated social vulnerability index.

CI Economic

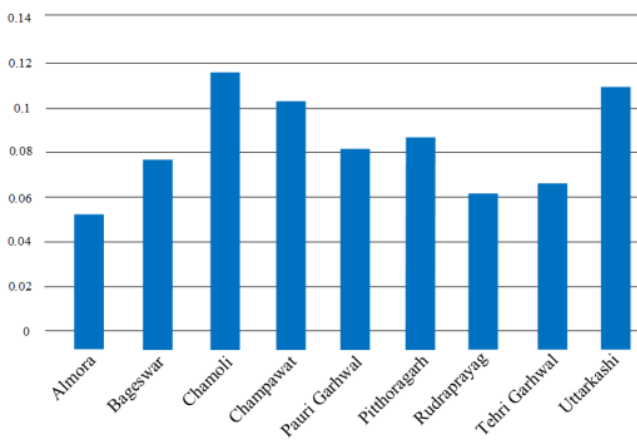

CI_Physical

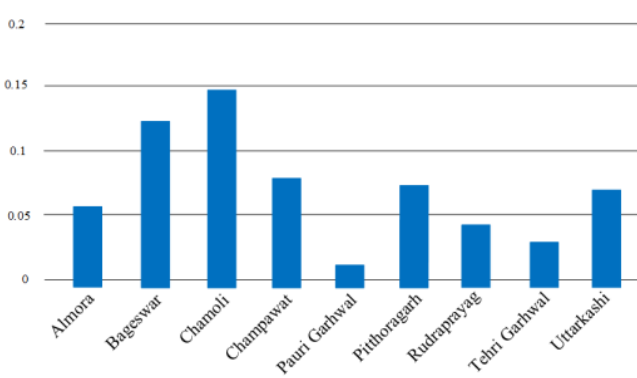

CI_Social

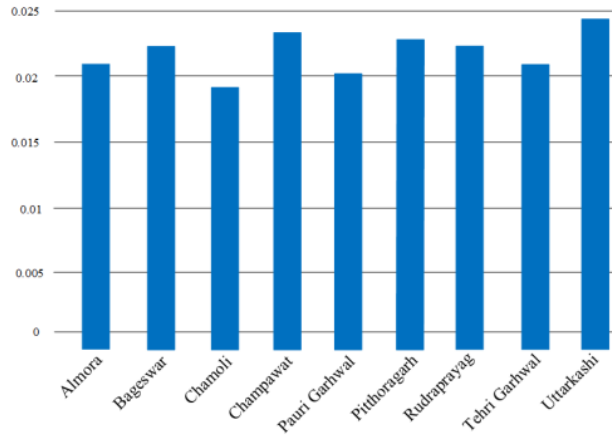

CI_Environmental

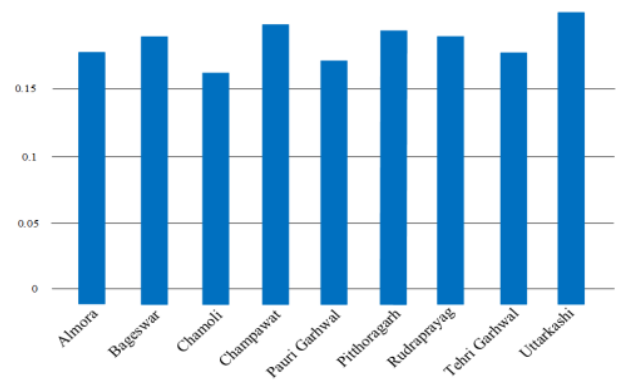

Fig. 6. Different components of integrated social vulnerability index.

All these index values are integrated into ArcGIS to prepare the vulnerability map of Uttarakhand. In Fig. 7 districts coloured in red have high vulnerability, the brown and brick colour districts are moving towards high vulnerability index and, if proper step are not taken in the near future, the situation in the areas may become alarming. Areas with smaller vulnerability index are coloured in green. 

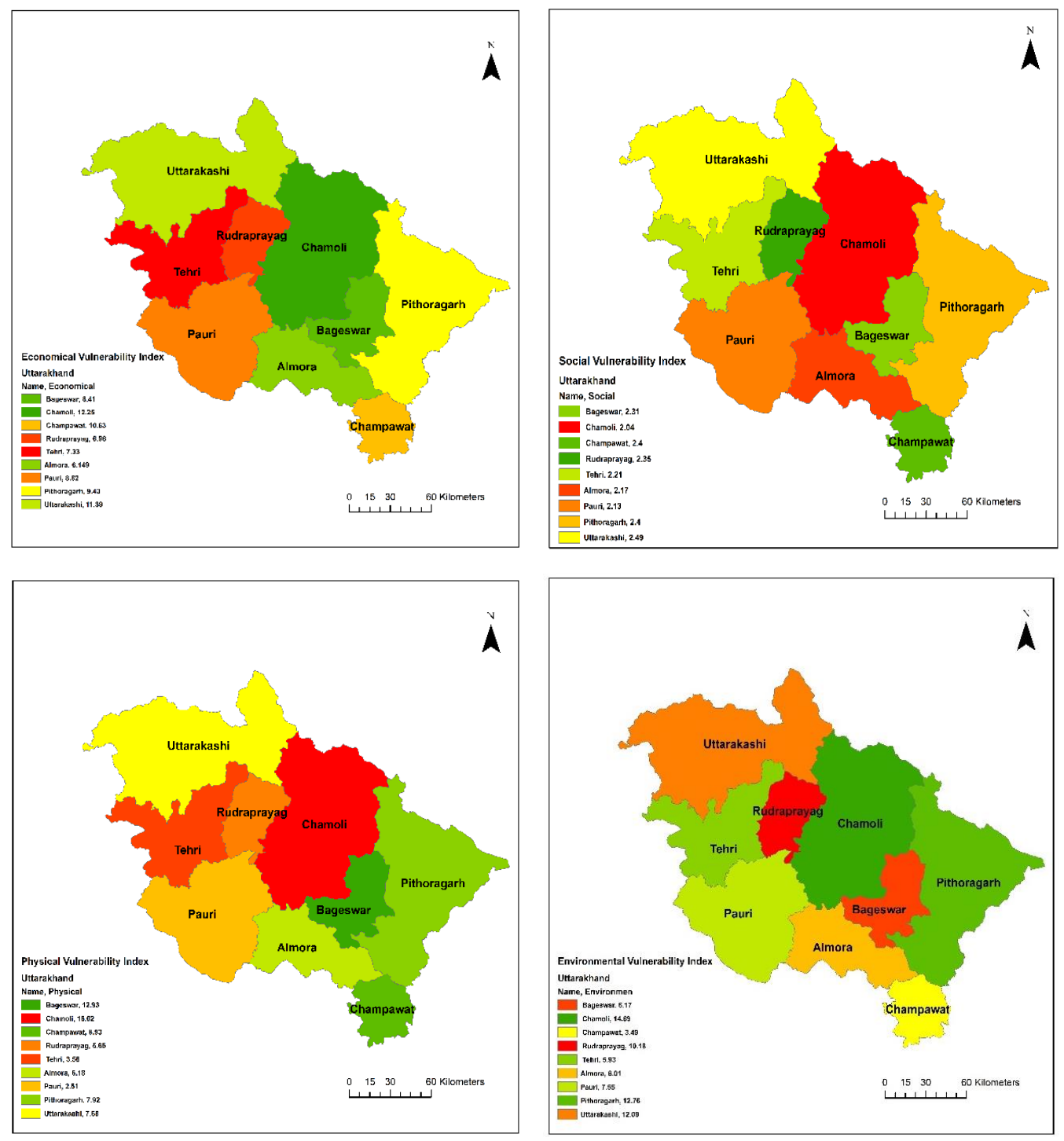

Fig. 7. Vulnerability map of different components of integrated social vulnerability index.

\subsection{Formulation of Integrated Social Vulnerability Index (SoVI int $_{\text {) }}$}

Fig. 8 shows the histogram of integrated social vulnerability index of Uttarakhand. The vulnerability components are integrated to get the integrated social vulnerability index SoVI as mentioned in Eq. (7). It is found that Tehri Garhwal has the least SoVI with a value of 0.19 and Chamoli has the highest SoVI with a value of 0.45 , followed by Pitthoragarh and Uttarkashi. The analysis of the results shows that the social vulnerability index provides indirect information about the development stage of different parts of Uttarakhand as well as indicates the areas of concern which are really affected by hazards like landslide, flood, unexpected migration and the basic 
facilities available to local citizen. Fig. 9 shows the integrated social vulnerability map of Uttarakhand.

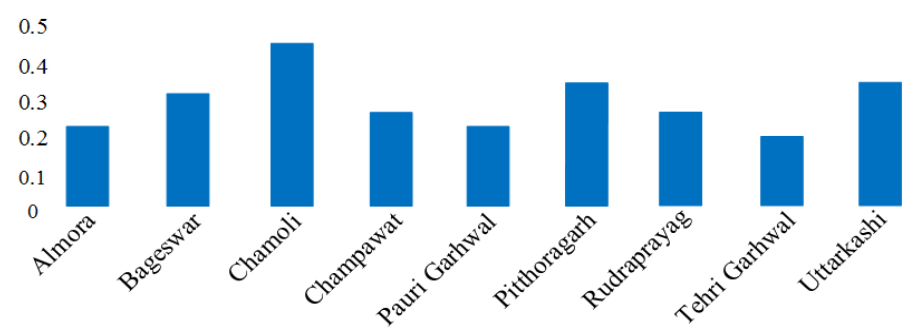

Fig. 8. Histogram of integrated social vulnerability index.

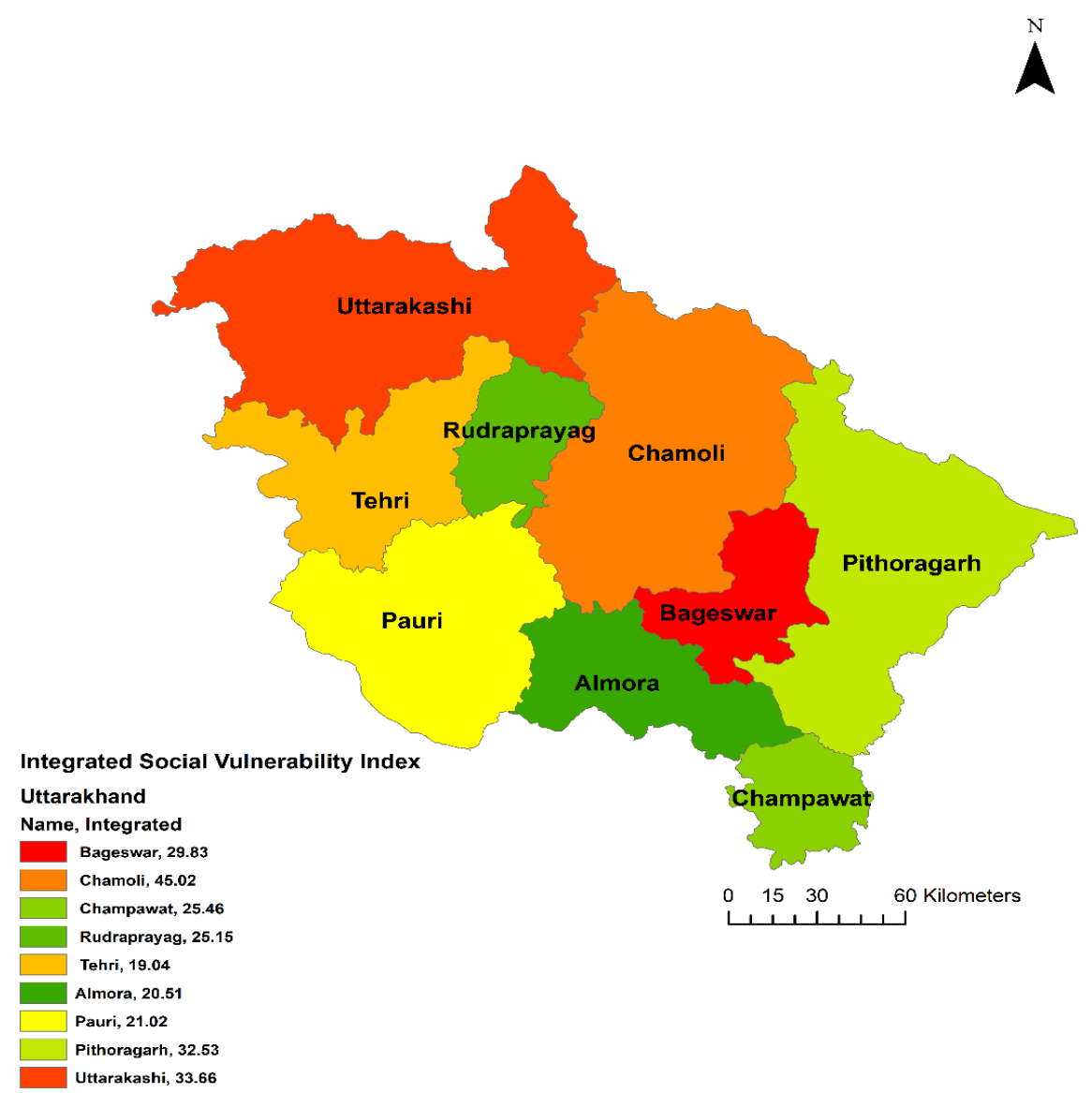

Fig. 9. Integrated social vulnerability index map of Uttarakhand. 


\subsection{Comparative Study of Presented Social Vulnerability with District Development Score}

The district development score is an index which indirectly shows the development of different districts in a state[43]. This score is prepared by considering following parameters like Income of the residents, Infrastructure available in the place, Health services available in the district, Education scenario, Employment and Tourism activity in the area [44]-[46]. In the present study the projected social vulnerability is like $D D S$, except in our vulnerability we consider the hydrological factors along with the factors included in the $D D S$ estimation. It should be mentioned here that the relation between vulnerability and $D D S$ is inverse in nature i.e. If $D D S$ for a district is higher than that district should be less vulnerable. The result of present study verifies the statement, since Almora has the highest $D D S$ and it is the least vulnerable place in our study. The Chamoli district has highest social vulnerability and thus least $D D S$. The comparative score of $D D S$ and Social vulnerability are shown in Fig. 10.

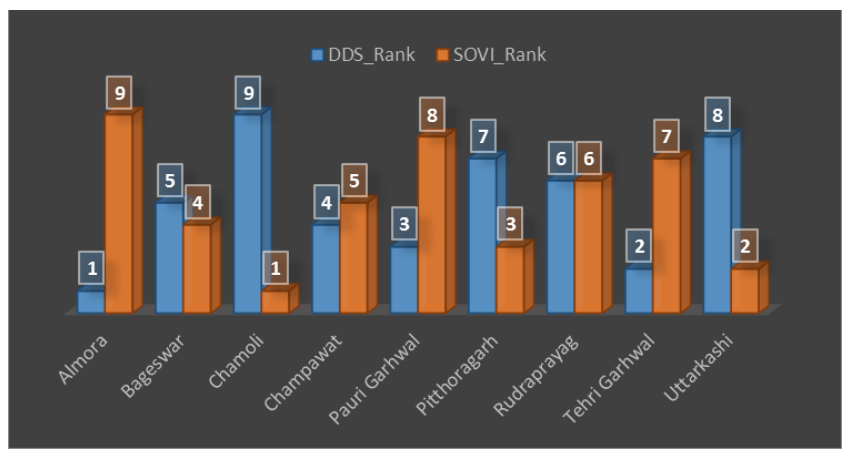

Fig. 10. A comparative chart between DDS and SoVI for Uttarakhand.

\section{Conclusions}

Identification of hot spot in terms of vulnerability represents a very important contribution to decrease and control the land, wealth and human life damage caused by different natural hazard. Development strategies forced the events like deforestation and urbanization, even then it is important. So, it is necessary to combine various hazards mitigation strategies with planning strategies. Remote sensing plays an important role in hazard assessment and its mitigation by identifying the surface with high erosion, deforestation and forest fire. The present study calculated district wise integrated social vulnerability index for hilly districts of Uttarakhand, India. A number of factors were selected in the preview that they will accurately represent the vulnerability of the different parts of the state. All the selected factor is firstly normalized and then used to formulate the different vulnerability index as physical, social, economic and environmental index. Integration of all these indexes provided us the final social vulnerability index.

The study shows that regions covering hilly areas like Chamoli and Uttarkashi are the most vulnerable districts of the state, and Almora is the least vulnerable, since Almora has some plane regions and the district is also situated at low altitude with respect to other region. So many factors like literacy, drug addiction, outmigration and unemployment play an important role in making hilly districts more vulnerable along with the hydrological factors. Such factors as outmigration, employment, and education have great impact on vulnerability, therefore, the solution related to these factors can be handled by policy makers. We should educate the young generation regarding 
the ill effects of drug addiction. The forestation will be useful to reduce the vulnerability. We should take step to prevent forest fire in hilly areas which is also a major factor towards the vulnerability. The results of the present study may be used by local authorities of the regions for better management of the livelihood of the residents.

\section{REFERENCES}

[1] Pranuthi G., Dubey S. K., Tripathi S. K., Chandniha S. K. Trend and change point detection of precipitation in urbanizing Districts of Uttarakhand in India. Indian Journal of Science and Technology 2014:7(10):1573-1582

[2] S. Kar. Inclusive Growth in Hilly Regions: Priorities for the Uttarakhand Economy. Institute of Economic Growth, 2007.

[3] Girdhar M. Comparative Geospatial Analysis of Uttarakhand forest fire (India) and Rocky forest fire in US. Presented at 17th ESRI India User Conference, 2017.

[4] Karmaoui A., Balica S. F., Messouli M. Analysis of applicability of flood vulnerability index in Pre-Saharan region, a pilot study to assess flood in Southern Morocco. Natural Hazards and Earth System Sciences, Discuss., 2016:1-24. https://doi.org/10.5194/nhess-2016-96

[5] Zvingule L, Kalnins S. N, Blumberga D., Gusca J., Bogdanova M., Muizniece I. Improved project management via advancement in evaluation methodology of regional cooperation environmental projects. Environmental and Climate Technologies 2013:11(1):57-67. https://doi.org/10.2478/rtuect-2013-0008

[6] Cardona O. D., van Aalst M. K., Birkmann J., Fordham M., McGregor G., Mechler R. Determinants of risk: exposure and vulnerability. Cambridge: Cambridge University Press, 2012.

[7] Fernandez P., Mourato S., Moreira M, Pereira L. A new approach for computing a flood vulnerability index using cluster analysis. Physics and Chemistry of the Earth, Parts $A / B / C$ 2016:94:47-55. https://doi.org/10.1016/j.pce.2016.04.003

[8] Balica S, Wright N. G. Reducing the complexity of the flood vulnerability index. Environmental Hazards 2010:9(4):321-339. https://doi.org/10.3763/ehaz.2010.0043

[9] Balica S. F. Applying the flood vulnerability index as a knowledge base for flood risk assessment. IHE Delft Institute of Water Education, 2012.

[10] Villordon M. B. B. Community-based flood vulnerability index for urban flooding: understanding social vulnerabilities and risks. PhD Thesis. Universite de Nice-Sophia Antipolis, 2015.

[11] Costa R. N., Machado C. J. S. Social and Environmental Vulnerability in Environmental Education Practiced Within the Federal Licensing in Macae (Rio De Janeiro, Brazil). Ambiente\&Sociedade 2017:20(1):127-146. https://doi.org/10.1590/1809-4422asoc20150057v2012017

[12] Flanagan B. E., Gregory E. W., Hallisey E. J., Heitgerd J. L., Lewis B. A Social Vulnerability Index for Disaster Management. Journal of Homeland Security and Emergency Management. 2011:8(1). https://doi.org/10.2202/1547-7355.1792

[13] Papagiannaki K., Lagouvardos K., Kotroni V., Bezes A. Flash flood occurrence and relation to the rainfall hazard in a highly urbanized area. Natural Hazards and Earth Systems Science 2015:15(8):1859-1871. https://doi.org/10.5194/nhess-15-1859-2015

[14] Das P. K. The Himalayan Tsunami - Cloudburst, Flash Flood \& Death Toll: A Geographical Postmortem. IOSR Journal of Environmental Science, Toxicology and Food Technology 2013:7(2):33-45. https://doi.org/10.9790/2402-0723345

[15] Pankaj G. Flash Flood and its Mitigation: A Case Study of Almora, Uttarakhand. India Journal of Environmental Hazards 2018:1:1-7.

[16] Dimri A. P., Chevuturi A., Niyogi D., Thayyen R. J., Ray K., Tripathi S. N., Pandey A. K., Mohanty U. C. Cloudbursts in Indian Himalayas: A review. Earth-Science Reviews 2017:168:1-23. https://doi.org/10.1016/j.earscirev.2017.03.006

[17] Pubule J., Kalnbalkite A., Teirumnieka E., Blumberga D. Evaluation of the Environmental Engineering Study Programme at University. Environmental and Climate Technologies 2019:23(2):310-324. https://doi.org/10.2478/rtuect-2019-0070

[18] Yucel G., Arun G. Earthquake and Physical and Social Vulnerability Assessment for Settlements: Case Study Avcilar District. Presented at World Conference on Earthquake Engineering, Lisbon, Portugal, 2012.

[19] Rimba A. B., Setiawati M. D., Sambah A. B., Miura F. Physical Flood Vulnerability Mapping Applying Geospatial Techniques in Okazaki City, Aichi Prefecture, Japan. Urban Science 2017:1(1):7. https://doi.org/10.3390/urbansci1010007

[20] Briguglio L., Cordina G., Farrugia N., Vella S. Economic Vulnerability and Resilience: Concepts and Measurements. Oxford Development Studies 2009:37(3):229-247. https://doi.org/10.1080/13600810903089893

[21] Adger W. N. Indicators of social and economic vulnerability to climate change in Vietnam. CSERGE GEC Working Paper 1998:42. 
[22] Punia M., Punia N. Socio-economic vulnerability and sustainable development in context of development vs. conservation debate: A study of Bhagirathi Basin, Uttarakhand, India. International Society for Photogrammetry and Remote Sensing 2014: XL-8/1:77-84. https://doi.org/10.5194/isprsarchives-XL-8-77-2014

[23] Ministry T., Government F. Assessment of Environmental Degradation and Impact of Hydroelectric projects during the June 2013 Disaster in Uttarakhand, Part I. Main Report, April, 2014. [Online] Available: https://sandrp.in/2014/04/29/report-of-expert-committee-on-uttarakhand-flood-disaster-role-of-heps-welcomerecommendations/.

[24] Kumar D., Himanshu S. K. Geographical Information Based Evaluation System for Drought. American Journal of Biological and Environmental Statistics 2017:3(4):49-53. https://doi.org/10.11648/j.ajbes.20170304.12

[25] Bejar-Pizarro M., Ezquerro P., Herrera G., Tomas R., Guardiola-Albert C., Hernandez J. M. R., Merodo J. A. F., Marchamalo M., Martinez R. Mapping groundwater level and aquifer storage variations from InSAR measurements in the Madrid aquifer, Central Spain. Journal of Hydrology 2017:547:678-689. https://doi.org/10.1016/j.jhydrol.2017.02.011

[26] Miezis M., Zvaigznitis K., Stancioff N., Soeftestad L. Climate change and buildings energy efficiency - The key role of residents. Environmental and Climate Technologies 2016:17(1):30-43. https://doi.org/10.1515/rtuect2016-0004

[27] Fekete A. Assessment of Social Vulnerability for River-Floods. United Nations University - Institute for Environmental and Human Security. Thesis, 2009.

[28] Zurovec O., Cadro S., Sitaula B. Quantitative Assessment of Vulnerability to Climate Change in Rural Municipalities of Bosnia and Herzegovina. Sustainability, 2017:9(7):1208. https://doi.org/10.3390/su9071208

[29] Gebreyes M., Theodory T. Understanding social vulnerability to climate change using a 'riskscapes' lens: Case studies from Ethiopia and Tanzania. Erdkunde 2018:72(2):135-150. https://doi.org/10.3112/erdkunde.2018.02.05

[30] Yan X., Li X. Evaluation on social vulnerability to natural disasters. The Anthropologist 2016:24(2):570-580. https://doi.org/10.1080/09720073.2016.11892051

[31] Costa H., Dias L., Grosso N., Garrett P. National flood vulnerability index, 2014.

[32] Flanagan B. E., Hallisey E. J., Gregory E. W., Heitgerd J. L., Lewis B. The Social Vulnerability Index and Toolkit. Journal of Homeland Security and Emergency Management 2013:8(1):1547-7355. https://doi.org/10.2202/1547-7355.1792

[33] Frigerio I., Carnelli F., Cabinio M., De Amicis M. Spatiotemporal Pattern of Social Vulnerability in Italy. International Journal of Disaster Risk Science 2018:9(2):249-262. https://doi.org/10.1007/s13753-018-0168-7

[34] Wijaya A. P., Hong J. H. Quantitative assessment of social vulnerability for landslide disaster risk reduction using gis approach (case study: Cilacap regency, province of central Java, Indonesia). International Society of Photogrammetry and Remote Sensing 2018:XLII-4:703-709. https://doi.org/10.5194/isprs-archives-XLII-4703-2018

[35] Chakraborty A., Joshi P. K. Mapping disaster vulnerability in India using analytical hierarchy process. Geomatics, Natural Hazards and Risk 2017:7(1):308-325. https://doi.org/10.1080/19475705.2014.897656

[36] Bahinipati C. S. Assessment of vulnerability to cyclones and floods in Odisha, India: a district-level analysis. 2004:107:(12):1997-2007. [Online]. Available: https://www.jstor.org/stable/24216033.

[37] Bhadra A., Bandyopadhyay A., Hodam S., Yimchungru C. Y., Debbarma R. Assessment of Vulnerability of Arunachal Pradesh (India) to Floods. Presented at Int. Water Resource Association Congr., 2015.

[38] Karmeshu N. N., Scatena F. Trend Detection in Annual Temperature \& Precipitation using the Mann Kendall Test - A Case Study to Assess Climate Change on Select States in the Northeastern United States. Mausam 2015:66(1):1-6.

[39] Mujumdar P. P. Implications of climate change for sustainable water resources management in India. Physics and Chemistry of the Earth, Parts A/B/C 2008:33(5):354-358. https://doi.org/10.1016/j.pce.2008.02.014

[40] Aneseyee A. B. The Effect of Climate Change on Water Resources Potential of Omo Gibe Basin, Ethiopia. Environmental Engineering 2013. https://doi.org/10.21203/rs.2.19417/v1

[41] Huang Y., Zou Y., Huang G., Maqsood I., Chakma A. Flood vulnerability to climate change through hydrological modeling: A case study of the swift current creek watershed in Western Canada. Water International 2009:30(1):31-39. https://doi.org/10.1080/02508060508691834

[42] Gupta S. Modeling district level economic disparities across Uttarakhand, India. IOSR Journal of Humanities and Social Science 2014:19(2):84-90. https://doi.org/10.9790/0837-19258490

[43] Yadav A. S., Pandey D. C. Demographic Attributes and Population Dynamics: Study from Himalayan State of Uttarakhand, India. 2017:22(8):50-57.

[44] Uttarakhand Action Plan on Climate Change: Transforming Crisis into Opportunity, 2014. [Online] Available: http://www.forest.uk.gov.in/files/USAPCC/Uttarakhand_SAPCC.pdf.

[45] Chambers S. Uttarakhand: Disaster as a Tragedy. Critical Concerns, 2013. [Online]. Available: http://www.doccentre.net/cc/cc_uttarakhand.pdf. 


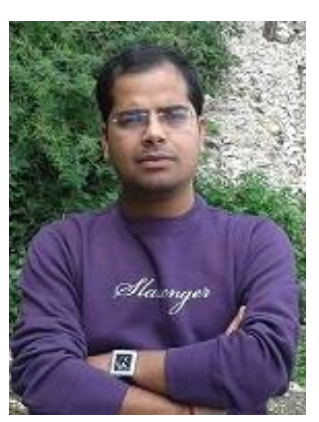

Dilip Kumar, Assistant Professor at the Govind Ballabh Pant Engineering College, Pauri, Uttarakhand, Faculty of Civil Engineering, Department of Civil Engineering. D. Kumar obtained the B. Tech. degree in Agricultural Engineering at the Allahabad Agricultural University in 2008, the M. Tech and the Ph.D. (P) degree from the IIT Guwahati in Water Resource. He is an associate member of the American Society of Civil Engineering (ASCE). Research interests are related to studies of climate change, flood vulnerability analysis, and flood modelling.

E-mail: jhadilip27@gmail.com

ORCID iD: https://orcid.org/0000-0001-8575-0086

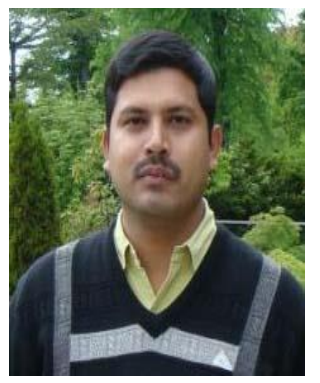

Rajib Kumar Bhattacharjya, Professor at Indian Institute of Technology, department of Civil Engineering, Guwahati, India. Worked at National Institute of Technology Silchar (July 1997 - May 2008) and Jorhat Engineering College, Jorhat Assam (May 1995 - July 1997), then Indian Institute of Technology Guwahati. Received the Bachelor degree in 1993 and the Master degree in Civil Engineering from Gauhati University, India in 1995. Has the Ph.D. in Civil Engineering from Indian Institute of Technology Kanpur, India (2004). The Ph.D. thesis title: "Management of salt-water intrusion in coastal aquifers using ANN-GA based simulation optimization approach". Current research interests: coupled simulation-optimisation modelling for groundwater management, identification and management of virus sources in groundwater aquifers, management of saltwater intrusion in coastal aquifers, optimisation methods and artificial neural networks. He has more than 20 years of teaching and research experience. Author of more than 70 peer-reviewed scientific publications in various reputed international journals and conference proceedings. A visiting professor at other institutes, including the Dalhousie University, Halifax, Canada, Ecole Centrale Nantes, France and National Institute of Technology Meghalaya.

ORCID iD: https://orcid.org/0000-0003-4681-3480 